\title{
Pencapaian pedagogical content knowledge melalui pembelajaran matematika
}

\section{Sri Yunita Ningsih*}

STKIP Insan Madani Airmolek, Jl. Jenderal Sudirman Tanah Tinggi Airmolek I, Pasir Penyu, Indragiri Hulu, Riau, Indonesia, 29352

Departemen Pendidikan Matematika, Sekolah Pascasarjana Universitas Pendidikan Indonesia, Jl. Dr. SetiaBudhi No. 229, Bandung, Indonesia, 40154

\section{Muhammad Daut Siagian}

Universitas Islam Sumatera Utara, Jl. Sisingamangaraja, Teladan-Medan, Indonesia, 20217

Departemen Pendidikan Matematika, Sekolah Pascasarjana Universitas Pendidikan Indonesia, J1. Dr. SetiaBudhi No. 229, Bandung, Indonesia, 40154

\section{*Corresponding Author: sriyunitaningsih89@gmail.com}

\begin{abstract}
Pedagogical content knowledge is a combination of understanding of teaching material (content knowledge) and understanding how to educate (pedagogical knowledge) that needs to be possessed by a teacher. The purpose of this study was to determine the pedagogical content knowledge concept, the achievement of pedagogical content knowledge for prospective teacher students, and to determine the role of prospective mathematics teacher students towards pedagogical content knowledge. A teacher in carrying out his professional assignments must have the competence that is always maintained. Because of this, competency development is an important requirement to ensure that the quality of learning in the classroom adjusts to the development and demands of the times. Always maintained competence also ensures that the implementation of education is consistent in achieving educational goals. There are ten pedagogical content knowledge criteria that must be possessed by prospective teacher students before conducting the practice in the field. Prospective teacher students must also be able to implement learning, knowledge of ways to represent and explain the material to make the material understandable to others.
\end{abstract}

Historis Artikel:

Diterima: 4 Maret 2020

Direvisi: 10 Maret 2020

Disetujui: 29 Maret 2020

\section{Keywords:}

Pedagogical content knowledge, mathematics learning

Sitasi: Ningsih, S. Y., \& Siagian, M. D. (2020). Pencapaian pedagogical content knowledge melalui pembelajaran matematika. Journal of Didactic Mathematics, 1(1), 41-46. https://doi.org/10.34007/jdm.v1i1.157

\section{PENDAHULUAN}

Hasil belajar siswa dalam bentuk prestasi belajar merupakan sebuah produk dari pembelajaran berkualitas yang difasilitasi oleh guru. Dalam mengelola pembelajaran berkualitas dibutuhkan pengetahuan guru yang komprehensif. Kegiatan belajar mengajar merupakan perwujudan pengetahuan guru di kelas. Pengetahuan guru menentukan kualitas seorang guru yang pada akhirnya berpengaruh terhadap pencapaian hasil belajar siswa (Darling-Hammond, 2000). Ada lima macam dasar belajar untuk menyediakan pendidikan yang berkualitas dan membina manusia yang berkelanjutan yakni learning to know, learning to be, learning to live together, learning to do, dan learning to transform oneself and society (Ningsih \& Juandi, 2019).

Guru adalah salah satu faktor penentu keberhasilan dalam proses pembelajaran, dimana guru harus memiliki pengetahuan dan pemahaman yang mendalam terhadap materi ayang akan diajarkannya. Guru harus memiliki pengetahuan yang mendalam tentang bagaimana cara mengajarkan materi yang biasa disebut dengan pengetahuan pedagogik (pedagogic knowledge), bukan hanya itu saja pastilah seorang guru pun harus memiliki pendalaman materi yang akan diajarkan, 
kemampuan ini biasa disebut content knowledge. Banyak yang beranggapan jika seorang guru pendalaman materinya baik maka pasti dapat mengajar dengan baik, hal ini belum tentu tercapai jika seorang guru tidak memiliki pengetahuan pedagogik, perbaduan pemahaman dan pengetahuan akan cara mengajar yang baik dan tepat (Silverman \& Thompson, 2008) ini biasa disebut oleh Shulman (Ball, Thames, \& Phelps, 2008) sebagai pengetahuan konten pedagogik (Pedagogical Content Knowledge).

Perkembangan dunia pendidikan selalu menjadi trend dan topik yang menarik untuk diperbincangkan. Sistem kurikulum hingga pelaksanaan pembelajaran selalu mengalami perubahan baik pada tataran teori maupun pelaksanaannya. Begitupun halnya dalam pendidikan matematika. Pada tingkat sekolah dan perguruan tinggi,pembelajaran matematika juga selalu menarik untuk dibahas. Hasil belajar matematika yang maksimal, segala cara akan ditempuh. Baik melalui penerapan model-model pembelajaran hingga pendekatan pembelajaran yang bervariatif. Keberhasilan pembelajaran matematika tidak hanya didukung oleh keahlian guru dalam menyajikan materi tetapi guru dapat mengkombinasikan materi yang dalam kehidupan nyata peserta didik.

Shulman mengemukakan gagasan tentang Pengetahuan Konten Pedagogik untuk menjawab "pengetahuan apa yang harus dimiliki oleh guru?" (Silverman \& Thompson, 2008). (Shulman, 1987) dan Loughran et al (2008) menyatakan bahwa pengetahuan konten dan pedagogis harus dipadukan dalam pembelajaran untuk menciptakan pengetahuan baru. Hal tersebut didefinisikan sebagai Pedagogical Content Knowledge (PCK). Lebih lanjut, Shulman $(1986,1987)$ menyatakan bahwa PCK merupakan pengetahuan khusus yang dimiliki oleh guru mengenai bagaimana mengajar content tertentu kepada peserta didik dengan strategi yang mampu mengarahkan menuju pemahaman.

Pengetahuan konten pedagogik guru matematika sudah sering menjadi subjek penelitian (Ball, Lubienski, \& Mewborn, 2001). Hasil penelitian (Hill, Rowan, \& Ball, 2005) menunjukkan bahwa terdapat hubungan yang sangat erat antara pengetahuan guru dan prestasi belajar matematika siswa. Hasil penelitian (Schoenfeld, \& Kilpatrick, 2008) menunjukkan hal yang serupa, pengetahuan konten pedagogik guru matematika berdampak pada pembelajaran yang lebih efektif.

Pemerintah Indonesia menyadari pentingnya kompetensi guru dalam pencapaian pendidikan berkualitas. Karena itu, pemerintah menetapkan empat standar kompetensi yang harus dipenuhi oleh guru. Undang-Undang Republik Indonesia Nomor 14, 2005 tentang Guru dan dosen. Hal ini meliputi empat kompetensi: (1) kompetensi pedagogi yaitu pemahaman terhadap siswa, perancanagan dan pelaksanaan pembelajaran, evaluasi hasil belajar, serta membangun siswa untuk mengaktualisasikan berbagai potensi yang dimilikinya; (2) kompetensi professional yaitu penguasaan materi pembelajaran secara luas dan mendalam; (3) kompetensi kepribadian yaitu kemampuan personal yang mencerminkan kepribadian yang mantap, stabil, dewasa, arif, dan berwibawa, menjadi teladan bagi siswa, dan berakhlak mulia; dan (4) kompetensi social yaitu kemampuan guru untuk berkomunikasi dan bergaul secara efektif dengan siswa, sesame guru, tenaga kependidikan, orang tua/wali siswa, dan mayarakat sekitar. Penjabaran keempat kompetensi tersebut dideskripsikan dalam Peraturan Menteri Pendidikan Nasional No 16 tahun 2007 mengenai standar kompetensi guru.

Seorang guru dalam menjalankan tugas profesionalnya harus memiliki kompetensi yang selalu terjaga. Karena itu pengembangan kompetensi, merupakan syarat penting untuk menjamin bahwa kualitas pembelajaran dikelas menyesuaikan diri dengan perkembangan dan tuntutan zaman. Kompetensi yang selalu terjaga juga memastikan bahwa pelaksanaan pendidikan konsisten dalam pencapaian tujuan pendidikan (Lasauskien, Rauduvait, Barkauskait, 2014). Pentingnya studi akan pendidik guru memahami layanan awal keputusan guru untuk pedagogis selama program persiapan guru (Prachagool, Nuangchalerm, Subramaniam, \& Dostál, 2016).

Menurut (Day, 1999) Pengembangan profesional merupakan pengalaman belajar baik yang diperoleh secara alami maupun melalui kegiatan sadar dan terencana dan berkontribusi terhadap peningkatan kualitas pembelajaran di kelas. Pengembangan professional guru sangat menentukan kualitas pembelajaran di kelas. Pemerintah menyadari pentingya pengembangan profesional guru 
Pencapaian pedagogical content knowledge melalui...

secara berkelanjutan. Sehingga diterbitkanlah (Permennegpan RB no tahun 2009 yang menempatkan pengembangan keprofesian berkelanjutan sebagai komponen utama pengembangan karir guru. Seorang guru professional tidak hanya berkewajiban melaksanakan tugas belajar mengajar di kelas, tetapi juga bertanggung jawab mengembangkan profesinya secara berkelanjutan.

\section{METODE}

Jenis penelitian ini adalah penelitian kualitatif. (Creswell, 2009) menyatakan bahwa "qualitative research is means for exploring and understanding the meaning individuals or groups ascribe to a social or human problem. The process of research involves emerging questions and procedures: collecting data in the participants' setting; analy zing the data inductively, building form particulars to general themes; and making intepretations of the meaning of data. The final written report has a flexible writing structure. Metode yang digunakan dalam penelitian ini adalah metode deskripsi. Analisis secara deskriptif dilakukan dengan cara mencatat data, sajian data, penarikan kesimpulan, dan verifikasi (Miles, Huberman, \& Saldaña, 2014). Hasil penelitian didapat dari hasil kajian beberapa literatur. Literatur tersebut didapat dari beberapa buku teori dan jurnal internasional.

\section{HASIL DAN PEMBAHASAN}

Mengajar merupakan tugas yang kompleks, dalam menjalankannya dibutuhkan kompetensi yang memadai. Karena itu, dalam menjalankan tugas profesionalnya seorang guru perlu didukung oleh seperangkat kemampuan atau kompetensi. Pengetahuan atau kompetensi tersebut merupakan perpaduan dari penguasaan materi dan penguasaan tentang cara mengajar. Pengetahuan tentang integrasi pengetahuan materi ke dalam pengetahuan tentang kurikulum, pembelajaran dan karakteristik siswa, selanjutnya dikenal dengan Pedagogical Content Knowledge, atau dalam bahasa Indonesia lebih dikenal dengan pengetahuan konten pedagogik (Shulman, 1986).

Istilah Pedagogical Content Knowledge (PCK) atau pengetahuan konten pedagogik diperkenalkan pertama kali oleh Lee Shulman pada tahun 1986. Lee Shulman melalui komunitas penelitiannya berkolaborasi dalam proyek Knowledge Growth in Teaching (KGT). Proyek penelitian ini mengkaji pengetahuan yang harus dimiliki oleh guru dalam mengembangkan pembelajaran. Pengetahuan tersebut meliputi pengetahuan tentang konten dan pengetahuan tentang cara mengajar. Shulman menggunakan istilah Pedagogical Content Knowledge (PCK) sebagai perpaduan dari tiga pengetahuan guru, yakni subject matter knowlegde, pedagogical knowlegde, and knowlegde of context (De Miranda, 2008).

Shulman mengemukakan gagasan tentang pengetahuan konten pedagogik untuk menjawab "pengetahuan apa yang harus dimiliki oleh guru?" (Silverman \& Thompson, 2008). Pada saat itu berkembang pemahaman bahwa pengetahuan tentang materi (subject matter knowledge) dan Pengetahuan tentang cara mengajar (pedagogical knowledge) merupakan penentu utama keberhasilan guru dalam mengajar. Hasil penelitian Shulman dan kolega menunjukkan bahwa Pengetahuan konten pedagogik merupakan penentu utama keberhasilan guru dalam pembelajaran. Meskipun demikian, pengetahuan konten pedagogik tidak bisa dipisahkan dengan pengetahuan konten dan pengetahuan pedagogik.

Menurut (Loughran, Berry, \& Mulhall, 2006). Pengetahuan konten pedagogik merupakan suatu konsttruksi akademik yang menggambarkan suatu ide yang dapat membangkitkan minat untuk mempelajari sesuatu. (Gess-Newsome, 1999) dalam studinya mengemukakan ada tiga pengetahuan yang harus dikuasai guru, yaitu pengetahuan konseptual, pengetahuan tentang struktur materi, dan pengetahuan tentang orientasi konteks spesifik dalam mengajar.

Shulman (Shulman, 1986) mengemukakan bahwa Pengetahuan konten pedagogik terdiri atas: (1) pengetahuan tentang cara-cara mempresentasikan dan menjelaskan suatu materi untuk membuat materi itu dapat dipahami, (2) pengetahuan tentang berpikir siswa, khususnya pengetahuan tentang konsepsi, dan prakonsepsi siswa yang berbeda usia dan latar belakang yang mereka bawa ke dalam belajar dan (3) PCK juga mencakup suatu pemahaman tentang apa yang membuat pelajaran tentang topik tertentu mudah atau sulit. 
PCK adalah pengetahuan tentang apa, kapan, mengapa dan bagaimana mengajar menggunakan pengetahuan yang baik tentang praktek dan pengalaman mengajar. Sehingga PCK dapat digambarkan sebagai berikut:

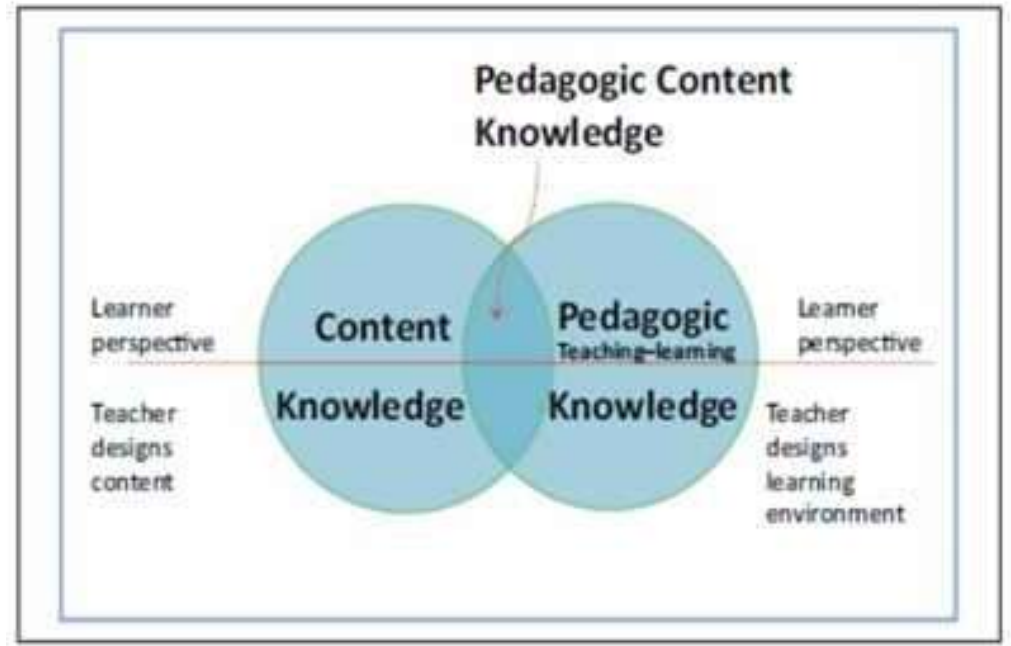

Gambar 1. Domains of Pedagogical Content Knowledge (Shulman, 1986)

Terkait dengan Pedagogical Content Knowledge (PCK) yang terdiri dari content knowledge dan pedagogical knowledge yang seharusnya dimiliki olaeh seorang guru, pemerintah Republik Indonesia pun sebenarnya tealah mengatur hal tersebut melalui PP No. 17 tahun 2008. Content knowledge ini menurut PP No. 74 tahun 2008 adalah kompetensi professional guru yaitu merupakan guru dalam menguasai pengetahuan bidang ilmu pengetahuan, teknologi, senidan budaya yang diampunyayang sekurang-kurangnya meliputi penguasaan materi pelajaran secara luas dan mendalam sesuai dengan standar isi program satuan pendidikan, mata pelajaran dan kelompok mata pelajaran yang akan diampu, konsep dan metode disiplin keilmuan, teknologi atau seni yang relevan yang secara konseptual menaungi atau koheren dengan program satuan pendidikan, mata pelajaran, kelompok mata pelajaran yang akan diampu.

Pada tahun 1987 Shulman menulis kembali tentang PCK, di dalam tulisan itu, Shulman kembali memberi penjelasan tentang PCK. Pada saat itu ia mengidentifikasi terdapat 7 kategori pengetahuan yang seharusnya dimiliki oleh guru agar dapat mengelola pembelajaran secara efektif. Tujuh kategori tersebut adalah (Shulman, 1987):

1) Content knowledge;

2) General pedagogical knowledge. With special reference to those broad principles and strategies of classroom management and organizaton that appear to transcend subject matter;

3) Curriculum knowledge, with particular grasp of the materaials ans programs that serve as "tools of the trade" fpr teachers;

4) Pedagogical content knowledge, that special amalgam of content and pedagogy that is uniquely the province of teachers, their own special form of professional understanding;

5) Knowledge of learners and their characteristics;

6) Knowledge of educational contexts, ranging from the workings of the group or classroom, the governance and financing of school districts, to the character of communities and culture;

7) Knowledge of educational ends, purposes, and valuea, and their philosophical and historical grounds.

Menurut Shulman, PCK merupakan suatu pengetahuan guru yang sangat khas: It represents the blending of content and pedagogy into an understanding of how particular topics, problems, or sissues are orgnized, represented, and adapted to the diverse interetsts and abilities of learners, and presented for instruction. Pedagogical content knowledge is the category most likely to distinguish the understanding of the content specialist from the pedagogue (Shulman, 1987). Pada bagian selanjutnya, Shulman menjelaskan: A second kind 
Pencapaian pedagogical content knowledge melalui...

of content knowledge is pedagogical content knowledge, which goes beyond knowledge of subject matter per se to the dimension of subjectc matter knowledge for teaching. I still speak of content knowledge here, but of the particular form of content knowledge the embodies the aspects of content most germane to its teachability (Shulman, 1987).

\section{KESIMPULAN}

Beberapa aspek PCK diidentifikasi oleh (Shulman, 1987) sebagai model penalaran pedagogik dalam fakta, pengembangan, aplikasi, dan komunikasi yang menunjukkan keterkaitan satu sama lain. Eksistensi dari definisi di atas, PCK adalah pengetahuan yang merupakan perpaduan antara pengetahuan konten dan pedagogik ke dalam pemahaman topik, masalah atau isu dan bagaimana pengetahuan yang dipadukan itu diorganisasi, sedemikian sehingga dapat diadaptasi dari beragam kemampuan dan minat siswa yang selanjutnya diimplementasikan pada pembelajaran, pengetahuan tentang cara-cara merepresentasikan dan menjelaskan suatu materi untuk membuat materinya dapat dipahami orang lain.

Beberapa peneliti menggunakan ide Shulman untuk mempelajari pengetahuan guru dalam berbagai bidang studi, termasuk matematika, misalnya (Borko, Eisenhart, Brown, Underhill, Jones, \& Agard, 1992; Even \& Tirosh, 1995; Leinhardt, Zaslavsky, \& Stein, 1990), dan lainnya. Hasilhasil penelitian tersebut disintesis dan dikembangkan oleh Ball dan Bass untuk mempelajari pekerjaan mengajar matematika dari sudut pandang matematika. Penelitian mereka dilakukan dengan cara mempelajari hasil rekam pengajaran Ball selama satu tahun, termasuk hasil pekerjaan siswa dan catatan guru.

Pedagogical knowledge menurut PP No. 74 tahun 2008 adalah kompetensi pedagogik guru, yaitu merupakan kemampuan pengelolaan pembelajaran peserta didik yang sekurang-kurangnya meliputi pemahaman wawasan atau landasan kependidikan, pemahaman terhadap peserta didik, pengembangan kurikulum/silabus, perancangan pembelajaran, pelaksanaan pembelajaran yang mendidik dan dialogis, pemanfaatan teknologi pembelajaran, evaluasi hasil belajar, serta pengembangan peserta didik untuk mengaktualisasi berbagai potensi yang dimilikinya. Hal tersebut menunjukkan bahwa pemerintah Republik Indonesia sudah sangat serius ingin membenahi pendidikan di negerinya agar bisa bersaing dengan negara lainnya.

\section{DAFTAR PUSTAKA}

Ball, D. L., Lubienski, S. T., \& Mewborn, D. S. (2001). Research on teaching mathematics: The unsolved problem of teachers' mathematical knowledge. (4th ed.). Handbook of research on teaching.

Borko, H., Eisenhart, M., Brown, C. A., Underhill, R. G., Jones, D., \& Agard, P.C. (1992). Learning to teach hard mathematics: Do novice teachers and their instructors give up too easily?. Journal for Research in Mathematics Education, 194-222.

Creswell, Jhon W. (2009). Research design; Qualitative, quantitative, and mixed methods approaches. Los Angeles.: Sage.

Darling-Hammond, L. (2000). Teacher quality and student achievement: A review of state policy evidence. 44.

Day, C. (1999). Developing teachers: The challenges of lifelong learning. Psychology Press.

De Miranda, M. A. (2008). Pedagogical content knowledge and technology teacher education: Issues for thought. Journal of the Japanese Society of Technology Education, 50, 17-26.

Even, R., \& Tirosh, D. (1995). Subject-matter knowledge and knowledge about students as sources of teacher presentations of the subject-matter. Educational Studies in Mathematics, (1), 1-20.

Gess-Newsome, J. (1999). Pedagogical content knowledge: An introduction and orientation. In examining pedagogical content knowledge. Springer Netherlands, 3-17.

Hill, H. C., Rowan, B., \& Ball, D. L. (2005). Effects of teachers' mathematical knowledge for teaching on student achievement. L, 42(2),. American Educational Research Journa, 42, 371-406.

Leinhardt, G., Zaslavsky, O., \& Stein, M.K. (1990). Functions, graphs, and graphing: Tasks.

Loughran, J., Berry, A., \& Mulhall, P. (2006). Understanding and developing Science teacher's pedagogical content knowledge. Rotterdam: Sense Publishers. 
Miles, M. B., Huberman, A. M., \& Saldaña, J. (2014). Qualitative data analysis a methods sourcebook. Amerikan: Sage publication.

Ningsih, S. Y., \& Juandi, D. (2019). Achievement of ESD (educational for sustainable development) through mathematics learning. Journal of Physics: Conference Series, 1157, 042056. https://doi.org/10.1088/1742-6596/1157/4/042056

Prachagool, V., Nuangchalerm, P., Subramaniam, G., \& Dostál, J. (2016). Pedagogical decision making through the lens of teacher preparation program, Journal for the Education of Gifted Young Scientists, 4(1), 41-52. http://dx.doi.org/10.17478/JEGYS.2016116351.

Schoenfeld, A. H, J., \& Kilpatrick, J. E. R. E. M. Y. (2008). Toward a theory of proficiency in teaching mathematics. International Handbook of Mathematics Teacher Education, 321-354.

Shulman, L. (1987). Knowledge and teaching: Foundations of the new reform. Harvard Educational Review, 57(1), 1-22.

Shulman, L. S. (1986). Those who understand: Knowledge growth in teaching. 11.

Silverman, J., \& Thompson, P. W. (2008). Toward a framework for the development of mathematical knowledge for teaching. Journal of Mathematics Teacher Education, 11(6), 499-511. https://doi.org/10.1007/s10857-008-9089-5

Undang-Undang Republik Indonesia Nomor 14. (2005). Tentang Guru Dan Dosen. 